\title{
NILAI-NILAI KEMANUSIAAN DALAM LAGU 'AKU RETANG BAO' DI MANGGARAI NUSA TENGGARA TIMUR
}

\author{
Welfebri Oswaldus Wiko \\ Pascasarjana, Universitas Negeri Yogyakarta \\ E-mail: febriwiko@gmail.com,
}

\begin{abstract}
Abstrak
Penelitian ini bertujuan untuk mengungkapkan tinjauan nilai-nilai etika nyanyian tradisi nenggo pada pertunjukan tari caci di Manggarai NTT. Penelitian ini merupakan penelitian kualitatif dengan menggunakan kajian etnografi, fenomenologi, dan hermeneutika. Penelitian ini dilakukan di Kabupaten Manggarai, Provinsi Nusa Tenggara Timur. Subjek penelitian ini adalah penari $\mathrm{caci}$, tokoh/tua adat setempat, pemerintah setempat, dan tokoh masyarakat setempat. Sumber data terdiri dari data primer dan data sekunder. Pengumpulan data dilakukan melalui observasi, wawancara, dan dokumen. Keabsahan data diperoleh melalui triangulasi dan dianalisis hingga menghasilkan sebuah kesimpulan. Hasil penelitian ini adalah sebagai berikut. Pertama, nyanyian tradisi "Aku Retak Bao" menjadi bagian yang tak terpisahkan dari kebudayaan Manggarai. Kedua, nilai-nilai kemanusiaan yang terkandung dalam nyanyian tradisi "Aku Retak Bao" meliputi: 1) nilai kesenangan, 2) nilai vitalitas, 3) nilai spiritual dan nilai kesucian, dan nilai spiritual meliputi tiga nilai pokok yang terdiri dari nilai estetis, nilai benar dan salah, dan nilai dari pengetahuan murni demi diri sendiri. Nilai Kesucian berkaitan dengan kepercayaan orang Manggarai di antaranya kepercayaan akan roh alam dan roh leluhur (ritus teing hang/takung dan ritus toto urat), kepercayaan akan adanya roh halus, benda dan ucapan magis, dan Mori Kerang (Tuhan Pencipta).
\end{abstract}

Kata kunci: nilai kemanusiaan, nyaanyian tradisi, Aku Retak Bao

\section{VALUES OF HUMANITY IN SONG 'AKU RETANG BAO' IN MANGGARAI NUSA TENGGARA TIMUR}

\begin{abstract}
This study aims to review the ethical values of Nenggo traditional song in the Caci dance performance in Manggarai, East Nusa Tenggara Province. This research is a qualitative study using ethnographic, phenomenological, and hermeneutic studies. This research was conducted in Manggarai Regency, East Nusa Tenggara Province. The subjects of this study were Caci dancers, local traditional leaders / figures, local government, and local community leaders. Data sources consist of primary data and secondary data. Data collection was done through observation, interviews, and documents. The validity of the data was obtained through triangulation and analyzed to produce a conclusion. The results of this study are as follows. First, the singing of "Aku Retak Bao" becomes an inseparable part of Manggarai culture. Second, the humanity values contained in the tradition singing "Aku Retak Bao" include: 1) the value of pleasure, 2) the value of vitality 3) the spiritual value and the value of purity, and the spiritual value includes three basic values consisting of aesthetic values, true and wrong values, and the value of pure knowledge for one's own sake. Purity Value relates to the beliefs of Manggarai people including belief in natural spirits and ancestral spirits (rites (riteteing hang/takung dan ritetoto urat), belief in the existence of spirits, magical objects and utterances, and Mori Kerang (God the Creator).
\end{abstract}

Keywords: humanity values, traditional singing, Aku Retak Bao 


\section{PENDAHULUAN}

Koentjaraningrat (1980: 193) mengungkapkan bahwa kebudayaan dimaknai sebagai keseluruhan sistem gagasan, tindakan, dan hasil karya manusia dalam kehidupan masyarakat yang dijadikan milik diri manusia dengan cara belajar. Kebudayaan daerah Nusa Tenggara Timur saat ini mengalami akulturasi dari berbagai daerah di Indonesia, namun masyarakat pendukung budaya tersebut masih mempertahankan ketradisionalan sebagai ciri khas yang tidak dimiliki oleh daerah lain. Manggarai adalah salah satu daerah di NTT yang juga memiliki ciri khasnya tersendiri. Keanekaragaman budaanya terdapat pada berbagai bentuk kesenian yang dimilikinya. Kesenian Manggarai adalah seni sastra (cerita-cerita rakyat), musik (terdapat alat musik sunding, gong, gendang, tambor, dan tinding biasanya dimainkan pada acara-acara kebudayaan), nyanyian tradisi Nenggo, tari (tari rangkuk alu dan tari caci sebagai tari khasnya) dan kriya (tenunan kain songke).

Dari berbagai cabang seni yang telah dipaparkan, nyanyian tradisi yang disajikan berupa syair-syair khas daerah merupakan salah jenis kesenian yang sangat melekat dengan kehidupan masyarakat Manggarai. Musik merupakan salah satu media komunikasi dimana dalam menyampaiannya berupa rentetan nada, ritme, tempo, melodi, dan syair yang dikombinasikan dan diatur sedemikian rupa untuk dapat dinikmati oleh pengapresiasi atau pendengar. Penggunaan unsur-unsur musik atau penggarapan secara musikal yang menarik menjadi hal utama dalam mengaransemen sebuah musik khususnya nyanyian-nyanyian tradisi.

Musik (nyanyian) tradisional Manggarai pada mulanya lebih mengutamakan syair dibandingkan unsur-unsur musik yang lainnya. Penggunaan syair-syair yang menarik dan nilai-nilainya harus dapat tersampaikan dan disimak dengan baik oleh para pendengar.Pada umumnya kebudayaan termasuk nyanyian tradisi memiliki nilai-nilai atau berperan dalam segala aspek kehidupan manusia. Lagulagu daerah Manggarai yang mengutamakan penyampaian nilai-nilai dan kerap kali menggunakan syair-syair yang sukar dipahami dalam penyajiannya. Pengapresiasi harus meninjau dengan mengamati dan menyimak secara mendalam dari setiap lagu-lagu yang diperdengar/dipertonotonkan.

Pada umumnya, lagu-lagu daerah (tradisi) sangat jarang diapresiasi oleh masyarakat khususnya kaum muda karena kemasan/ garapan yang tidak sesuai dengan kebutuhan masyarakat. Pesan moral dari setiap lagulagu tradisi yang dapat menjadi panutan hidup masyarakat sangat disayangkan apabila tidak diapresiasi oleh masyarakat itu sendiri. Salah satu modal utama manusia menjadi makhluk sosial adalah harus bermoral. Artinya dalam setiap kehidupannya harus mempunyai nilai positif. Sehingga moral merupakan sesuatu yang mutlakharus melekat pada diri manusia. Dalam kaitannya dengan budaya, moral merupakan produk dari budaya itu sendiri yang telah memiliki standar yang berbeda-beda sesuai dengan sistem nilai yang berlaku. Pesan moral yang disampaikan tentu saja sangat bermanfaat untuk dijadikan media mendidik generasi muda, baik melalui pendidikan nonformal maupun pada lembaga pendidikan formal.

Untuk mempermudah masyarakat dalam mengapresiasi setiap karya musik yang diperdengarkan, yang harus diperhatikan oleh kita sebagai pencipta musik (Arranger) adalah Aransemen atau garapan musik yang menarik. Dengan perkembangan zaman sekarang yang makin modern, setiap karya seni dapat dieksplor melalui berbagai macam media tekhnologi. Tetapi yang harus diperhatikan adalah, teknologi hanya menjadi unsur penunjang dalam merevitalisasi keseniankesenian tradisi. Teknologi hanya dapat dijadikan media untuk bagaimana pesan dari setiap karya seni tersampaikan di tengah kehidupan masyarakat.

\section{METODE}

Desain yang dipergunakan dalam penelitian ini akan bersandarkan pada pendekatan kualitatif. Dengan pendekatan 
ini, kiranya berbagai aspek yang diteliti akan dapat menghasilkan data yang valid, reliabel, dan relevan dengan yang dibutuhkan nantinya. Selain itu, dengan pendekatan kualitatif akan dapat dilakukan observasi dan wawancara yang lebih mendalam terhadap objek-objek penelitian, sehingga data-data yang diperoleh lebih akurat. Penelitian ini dilakukan di Manggarai, Nusa Tenggara Timur.

Teknik pengumpulan data yang dipergunakan dalam penelitian ini adalah dengan cara melakukan observasi, wawancara, dan dokumentasi. Adapun cara pengumpulan data dapat diperinci sebagai berikut: (1) Observasi, yakni cara yang dipergunakan peneliti untuk melihat proses pembelajaran seni tari. (2) Wawancara, yakni cara yang dipergunakan peneliti untuk mengungkap bagaimanakah para subjek penelitian memberi makna terhadap aktivitas proses pembelajaran seni tari. (3) Dokumentasi, yakni cara yang dipergunakan peneliti untuk meramu dan menempatkan terminologi dan sumber-sumber teori dalam penelitian ini.

Data yang terkumpul melalui hasil observasi, wawancara, dan dokumentasi ini berupadatakualitatif.Teknikyangdipergunakan untuk menganalisis data penelitian adalah teknik analisis deskriptif interpretatif dengan langkah-langkah sebagai berikut: (1) Memilih dokumen/data yang relevan dan memberi kode. (2) Membuat catatan objektif, dalam hal ini sekaligus melakukan klasifikasi dan mengedit (mereduksi) jawaban. (3) Membuat catatan reflektif, yaitu menuliskan apa yang sedang dipikirkan peneliti sebagai interpretasi dalam sangkutpautnya dengan catatan objektif. (4) Menyimpulkan data dengan membuat format berdasarkan teknik analisis data yang dikehendaki peneliti. (5) Melakukan triangulasi yaitu mengecek kebenaran data dengan cara menyimpulkan data ganda yang diperoleh melalui tiga cara: (1) memperpanjang waktu observasi di lapangan dengan tujuan untuk mencocokkan data yang telah ditulis dengan data lapangan, (2) mencocokkan data yang telah ditulis dengan bertanya kembali kepada informan, dan (3) mencocokkan data yang telah ditulis dengan sumber pustaka (Sutiyono, 2017).

\section{PEMBAHASAN \\ Bentuk lagu AkuRetangBao}

Lagu AkuRetang Bao menjadihal terpenting bagi para komposer atau pencipta lagu ketika menulis sebuah lagu. Struktur lagu merupakan segala sesuatu yang berkaitan dengan unsurunsur musik dalam sebuah lagu berupa intro, verse atau bridge, chorus, interlude, ending. Komposisi lagu yang bermakna ditentukan oleh pengolahan struktur yang menarik.Lagu Aku Retang Bao juga memiliki struktur yang dapat memaksimalkan penyampaian pesan yang disampaikan.

Berikut ini adalah lirik lagu Aku Retang Bao berdasarkan strukturnya;

\section{AKU RETAK BAO}

Intro:

Akuretangbao (2x)

Retangaparajan (2x)

Verse/Bridge:

Retangteangase kaeng sale Ruteng

Chorus:

Co' konglelon lite

Kepealikebe

Panggualiwatu

Sale Manggarai

Tundutenangase kaeng sale Ruteng

Dalam bahasa Indonesia, secara harafiah diartikan sebagai berikut;

\section{AKU MENANGIS}

Intro:

Tadi Saya menangis $(2 \mathrm{x})$

Menangis disebabkan karena apa? (2x)

Verse/Bridge:

Menangis ingat adik di Ruteng

Chorus:

Bagaimana kita bisa melihatnya

Dihalang bukit

Tertutup oleh bebatuan

Di Manggarai

Termenung Ingat Adik tinggal di Ruteng 
Berikut ini adalah partitur/musik original dari lagu Aku Retang Bao,

\section{Aku Retang Bao}

Lagu Tradisi Manggarai NTT

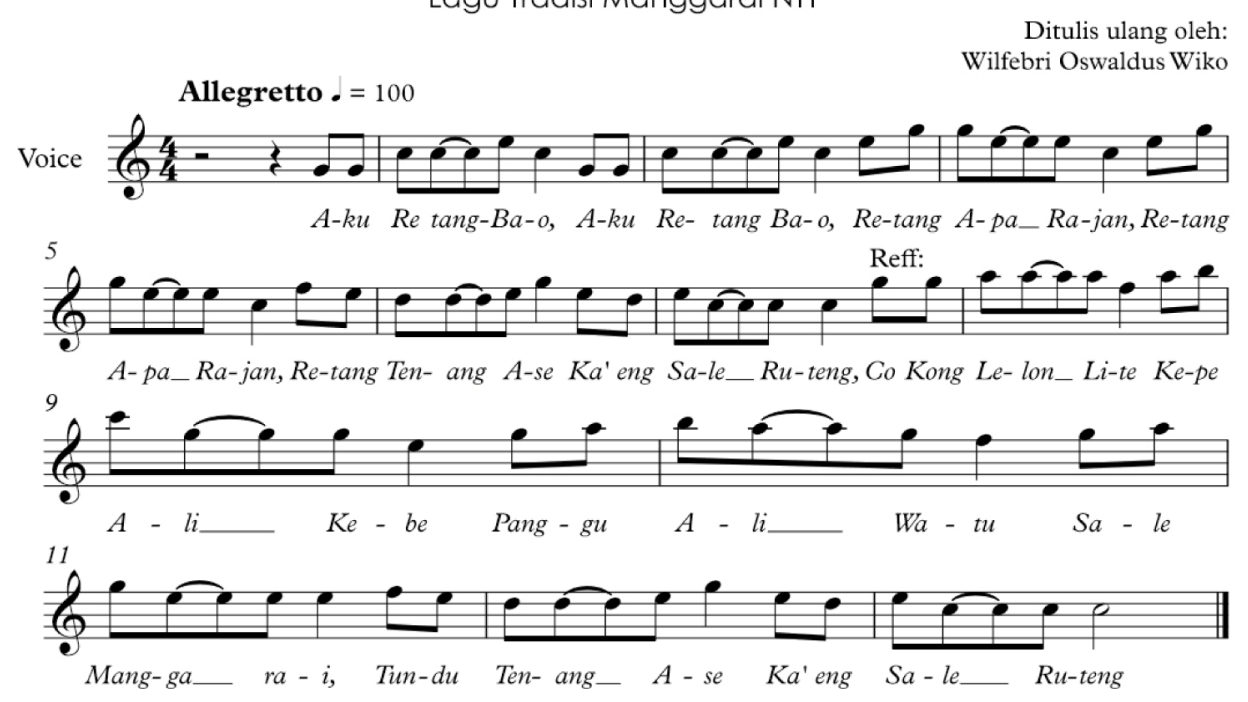

Gambar 1. Teks/ Partitur lagu Aku Retang Bao.

Partitur dibuat oleh Wilfebri Oswaldus Wiko, 2018.

Lirik-lirik yang terdapat pada lagu $A k u$ Retang Bao begitu sederhana jika kita artikan secara secara original dari setiap katanya. Jadi diceritakan bahwa seseorang yang sedang merindukan saudara (adik kandung) yang tinggal di Ruteng (Ibu kota kabupaten Manggarai). Pada umumnya jika lagu yang menceritakan atau yang menyampaikan pesan kesedihan, penggarapan musiknya tentu saja menggunakan musik dengan tempo lambat atau sedang. Kemudian warna musik yang dihasilkanpun tidak terkesan meriah. Inilah yang membedakan dari lagu Aku Retang Bao. Lagu yang menyampaikan kesedihan (tangisan) ini secara musik aslinya menggunakan tempo cepat, dan tidak terkesan lagu yang menceritakan kesedihan.

Berikut ini adalah dokumentasi dari salah satu group musik di Manggarai yang membawakan lagu Aku Retang Bao dengan menggunakann tempo cepat.

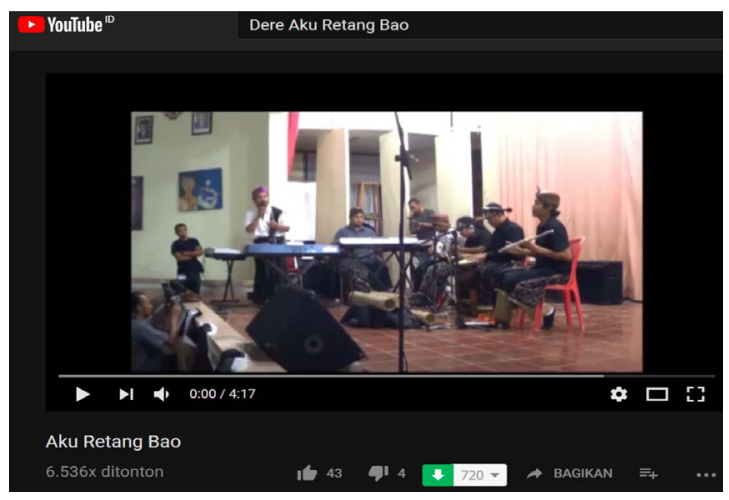

Dalam pertunjukan lagu Aku Retang Bao, penggarapan musiknya tidak seperti lagulagu kesedihan lainnya. Bahwa jika lirik yang menceritakan kesedihan (tangisan), maka garapan musik iringan dari lirik tersebut dapat mengaudiokan suasana dari pesan yang terdapat pada lirik. Pada garapan musik yang beranggotakan 6 (enam) orang ini mendapat respon meriah dari penonton (sorakan dan tepukan tangan). 
Lagu Aku Retang Bao yang dicover oleh Ivan Nestroman, cs (salah satu musisi Manggarai NTT) sangat dikemas dengan gaya musik modern, yang terdapat pada progresi chord dan melodi-melodi yang dimainkan. Pola aransemen atau gaya musik seperti ini tentu saja sangat melekat dengan kehidupan remaja, sehingga musik (lagu-lagu daerah) bukan menjadi hal yang kuno bagi para remaja ketika mengapresiasi.

Lagu Aku Retang Bao yang dinyanyikan oleh sekelompok siswa (peserta didik SDN Terang Golo Sepang, NTT dan diiringi musik rapai dari Aceh) masih sama seperti karakter aslinya.Ini merupakan hal yang wajar karena dengan kemampuan seusia anak sekolah dasar, masih mengikuti cara bernyanyi yang seperti biasanya. Tidak mengenal dengan adanya unsur improfisasi. Yang paling utama adalah bagaimana peserta didik belajar berdisiplin melalui seni.

LaguAkuRetang Baomerupakanlagutradisi Manggarai yang dulu kerap kali dinyanyikan oleh berbagai kelompok usia pada masyarakat Manggarai. Lagu yang berlirik singkat ini sangat muda untuk diperdengarkan/diketahui oleh masyarakat. Syair-syair yang digunakan juga tidak seperti pada lagu tradisi Manggarai lainnya seperti Nenggo yang menggunakan go'et-go'et dalam penyajiannya.

Bentuk lagu merupakan susunan dan hubungan antara unsur-unsur musik dalam suatu lagu sehingga menghasilkan suatu lagu yang bermakna. Bentuk ataupun struktur lagu itu merupakan susunan dan hubungan antara unsur musik dalam suatu lagu, sehingga menghasilkam suatu komposisi atau lagu yang bermakna atau mempunyai suatu arti. Komposisi adalah mencipta suatu lagu. Dasar pembentukan lagu mencakup pengulangan satu bagian lagu yang disebut repetisi, pengulangan dengan berbagai perubahan atau yang disebut dengan variasi ataupun sekuen, serta penambahan bagian yang baru yang berlainan atau berlawanan (kontras), dengan selalu memperhatikan keseimbangan antara pengulangan dan perubahannya.

\section{Nilai Kemanusiaan dalam lagu $A$ ku Retang Bao}

Beberapa nilai kemanusiaan yang terdapat dalam budaya masyarakat adat dalam lagu $A k u$ Retang $B a o$ (termasuk nilai-nilai nyanyian tradisi masyarakat Manggarai) memiliki keterkaitan antara satu nilai dengan nilai yang lainnya dan tidak dapat dipisahkan. Nialai-nila ikemanusiaanitusebagaiberikut.

1. Nilai Ketuhanan

Nilai ketuhanan, secara filosofis, berhubungan dengan nilai-nilai religius, yang pada umumnya bersifat suci atau kudus. Artinya, suci atau kudus merupakan bagian yang penting dalam prespektif ketuhanan (Bartens, 2002: 123), sehingga nilai ketuhanan selalu menyangkut objek-objek yang absolut, dan hanya terdapat pada bidang religius.

Nilai ketuhanan dapat diukur dengan memperhatikan fakta religius masyarakat, yang menurut van Peursen fakta memperoleh makananya dalam percakapan yang bersifat intersubjektif. Artinya, fakta hanya dapat terlihat jelas dalam konteks masyarakat atau kebudyaan khusus, yakni kebudayan masyarakat. Fakta tidak dapat dipisahkan dari jenis bahasa yang mengacu kepada fakta tersebut, sehingga fakta hanya dapat terlihat dalam keragaman dan nuansa penggunaan bahasa, yakni pada perlaku manusia. Nilai ketuhanan, atau yang dapat disebut juga sebagai nilai kesucian (kesopanan), hanya tampak pada manusia yang ingin menuju objek yang absolut itu melalui fakta religiusitas masyarakat, sehingga tidak tergantung pada dimensi ruang dan waktu. Ada dua perasaan yang selalu muncul pada nilai ketuhanan, yakni rasa terberkati dan rasa putus harapan. Kedua perasaan ini memang saling berlawanan, namun merupakan ceriminan, sekaligus ukuran kedekatan manusia pada "Yang Suci" itu. Unsur-unsur yang selalu ada, dan menjadi ukuran, di dalam upaya menegakkan nilai ketuhanan adalah beriman atau tidak beriman, menyembah atau tidak menyembah, memuji atau tidak memuji, dan membawa korban atau tidak membawa korban. Nilai-nilai ketuhanan, 
umunya, diaktualisasikan dalam bentuk do'a dan ibadah.

Salah satu unsur Nenggo atau syair-syair yangdigunakandalam Nenggo merupakango'et. Selain go'et yang tertera pada Nenggo 'Neka', berikut ini adalah salah satu contoh go' $e t$ khusus dalam hubungan dengan Tuhan;"Reme bokn toko bolek loke, moron, te tomor mori mowo". Pengertian ungkapan: Pada saat kehidupan senang, bahagia, sejahtera, dan kekayaan berlimpah sunguh-sunguh tidak mengenal (terlena dan tenggelam dalam kesenangan dan kekayaan materi) Tuhan Pencipta. Sementara manusia mengalami kebahagiaan, berkembang dan tak berkekurangan, ia tak mengenal Tuhan. Isi Ungkapan: Ada beberapa makna yang terkandung dalam go'et ini. Pertama, supaya manusia tidak terlena dan tenggelam dalam kesenangan dan kekayaan materi yang dimiliki sampai melupakan Tuhan sang pencipta dan pengada. Kesenangan dan kekayaan di dunia ini bersifat sementara dan relatif. Kedua, manusia diajak untuk tahu mengucap syukur atas segala kasih dan karunia yang telah Tuhan berikan kepada manusia. Antara do'a (torok) dan kerja harus ada keseimbangan.

\section{Nilai Kemanusian}

Manusia, melalui epistemologi, dipacu untuk selalu mempermasalahkan pengetahuannya. Epistemologi juga mempersoalkan kriteria tentang kepastian dan validitas pengetahuannya. Selain itu, ditumbuhkan pula kesadaran bahwa pengetahuan adalah pengetahuan manusia. Pernyataan ini hendak menegaskan bukan intelek atau rasio yang mengetahui, tetapi manusialah yang mengetahui; bukan rasio yang berpikir, tetapi manusialah yang berpikir melalui rasionya untuk kemanusiaan. Van Peursen, dalam pandangannya tentang kebudayaan untuk kemanusiaan, memberi penegasan tentang kebudayaan untuk kemanusiaan sebagai sebuah kebenaran mutlak yang perlu diketahui. Penegasannya jelas ketika menyebutkan bahwa kebudayaan adalah sebagian dari kemanusiaan manusia. Manusia baru akan menemukan kebudayaan, apabila manusia melihat dunia ini dalam sorotan rencana keberadaan manusia. Argumentasi Van Peursen ini terlihat pada kebudayaan masyarakat, sehingga untuk mengungkap nilai kemanusiaan pada pengetahuan budaya masyarakat penting mendasarinya dari pemikiran Van Peursen.

Nilai-nilai kemanusiaan merupakan prinsip dan tolok ukur yang dapat dikembangkan melalui kebenaran akan pengetahuan tentang budaya masyarakat, yang secara umum, lahir dari suatu kebudayaan yang realistis. Kebudayaan yang sangat realistis dan empiris adalah karya manusia untuk humanisme. Alasannya, seluruh kebudayaan yang diciptakan oleh manusia, pada kenyataannya ditujukan untuk keberlangsungan kehidupan manusia dan alam secara umum.

Nenggo yang erat kaitannya dengan nilai kemanusiaan salah satu contoh liriknya adalah; "Rai Ati, racang rak"; Pengertian ungkapan: melatih pikiran, kemauan, perasaan, kehendak, kecekatan, keterampilan dan keahlian manusia. Dengan lain perkataan, melatih dan mengembangkan seluruh potensi dan sumber daya yang dimiliki manuisa. Isi ungkapan: Nenggo berisi pesan dan nasihat yang disampaikan kepada anak-anak dan anggota keluarga supaya mereka bekerja keras, berjuang dengan sungguh-sungguh. Adapun yang menjadi sasaran dari nasihat ini adalah agar anak-anak melakukan pekerjaan yang diberikan kepadanya atau yang menjadi tanggung jawabnya, mencintai pekerjaan itu, sedapat mungkin mengambil contoh yang baik dari pekerjaan orang tua, mengembangkan kemauan berusaha untuk memenuhi kebutuhan hidup. Selain itu, Nenggo ini memacu semangat orang untuk selalu berusaha dengan tekun, memanfaatkan seluruh potensi yang ada dalam diri sendiri supaya bisa mandiri, memiliki inisiatif dan perlaku kreatif dan sanggup mengatasi tantangan. Melalui latihan yang terus menerus, bekerja keras, anak-anak atau generasi penerus dapat mengatasi tantangan hidup, menjadi dewasa dan matang dalam cara berpikir dan bertindak. 


\section{Nilai Sosialitas Masyarakat}

Nilai pada intinya merupakan cerminan jati diri seseorang atau kelompok. Nilai tersebut muncul dan berkembang sejalan dengan perkembangan diri atau kelompok tertentu, sehingga untuk mengungkapkan nilai-nilai yang terkandung dalam suatu budaya masyarakat perlu melihat hakikat dari budaya masyarakat itu sendiri. Pendapat ini sejalan dengan penjelasan Kattsoff (2004: 335), bahwa kaum pragmatis memahamkan hubungan antara nilai dengan "yang tahu" sedemikian rupa, dimana sesungguhnya nilainilai merupakan hasil ciptaan "yang tahu". Nilai selalu ditempatkan sebagai satuan-satuan yang merupakan kenyataan. Satuan-satuan ini sejak semula sudah terkandung dalam susunan kenyataan itu sendiri, sehingga ditinjau dari segi eksistensi, adanya segenap kenyataan tergantung pada yang bernilai.

Hakikat dari suatu kebudayaan masyarakat atau aspek ontologi budaya masyarakat diperlukan dalam rangka menggali nilai sosialitas yang terkandung pada esensinya suatu kenyataan, yakni masyarakat. Tujuannya mengungkapkan kandungan nilai pada budaya masyarakat.

Nenggo yang menceritakan atau bermakna nilai sosial masyarakat ialah Nenggo yang bersyair: "Nggoes wale oe, inggos wale io". Pengertian ungkapan: bersikap sopan, rendah hati,salingmenghormatidanmenghargai sesama manusia. Isi ungkapan dari Nenggo ini adalah berisi ajaran yang ditujukan kepada seluruh anggota masyarakat (pa'ang olon-ngaungn musin, wan koe-etan tu'a) untuk berperilaku, bertindak, dan bersikap sopan dalam membina pergaulan dan hubungan kerjas sama dengan orang lain. Nenggo yang menggunakan syair ini mempunyai makna yang dalam, khususnya menjadi norma bagi kehidupan masyarakat agar: menghindari perbuatan, tindakan, sikap dan perilaku yang bertentangan dengan norma-norma sopan santun yang berlaku dalam masyarakat. Di samping itu, syair ini juga memberikan penyadaran supaya setiap anggota masyarakat (lonto ca golo, $\mathrm{ka}$ 'eng ca beo) tahu menghormati dan menghargai harkat dan martabat serta persamaan dengan sesama manusia.

\section{Nilai Persaudaraan}

Ternyata segala sesuatu yang ada di muka bumi dapat menjadi berarti dan berharga jika memiliki nilai. Bukan saja benda yang bergerak, tetapi juga benda-benda yang tidak bergerak ternyata mengandung unsur nilai yang tinggi, dan membuatnya memiliki harga. Setiap manusia tidak kelihatan bukan saja tergantung dari sejauhmana orang itu memberi nilai terhadapnya, tetapi juga faktor benda atau barang tersebut telah memberikan manfaat bagi manusia.

Keberhargaan segala sesuatu, dalam masyarakat, terletak pada kehidupan sosial dan budayanya. Keberhargaan itu sejak dulu telah memberikan manfaat bagi manusia, baik intern maupun ekstern. Keberhargaan itu pula yang menjadikan komunitas masyarakat, beserta tradisi adat, budaya, agama, dan sosial, kemasyarakatannya tetap berkesistensi hingga kini.Halini dapatdipahami, sebabkeberhargaan dialamatkan kepada masyarakat berdasarkan penerapan nilai-nilai sosial dan budaya dalam seluruh kehidupan kemasyarakatannya.

\section{Nilai Kerukunan}

Dimensi kosmologi dalam masyarakat memberi penekanan bahwa alam bersama realitasnya, ternyata mengeksistensikan dirinya dalam wujud manusia yang utuh pada semua tatanan dinamis. Van Peursen (2003: 155) menyadari hal tersebut, sehingga kebudayaan, menurutnyaselaluberhubungandenganmanusia dan alam. Manusia mengenal kebudayaan, mengetahui refleksi, suka merenungkan diri, dan tidak dengan mudah menyerah pada alam sekitar, sehingga alam dipahami oleh manusia untuk menyususn rencana agar tidak dikuasai oleh kehendak alam (Sutiyono, 2011). Istilah yang tepat, yaitu manusia memanusiakan alam, dan itulah kebudayaan. Pemikiran Van Peursen ini menjadi dasar mengulas aspek nilai kerukunan dalam kosmologi masyarakat.

Kebudayaan adalah sebuah upaya memanusiakan alam, di mana manusia 
menganggap alam tidak sebagai sesuatu yang lain, namun yang dapat membantu manusia untuk mengatasi krisisnya di tengah-tengah alam semesta. Artinya, alam tidak selalu menjadi tantangan bagi manusia, melainkan dapat menjadi "sahabat" untuk manusia menjawab tantangan alam. Kosmologis seperti ini ingin menegaskan bahwa kuasa Supranatural (Tuhan), gunung, tanah, dan laut adalah gambaran masyarakat adat, terlihat secara nyata dalam sebuah organisme kehidupan yang utuh, saling bergantung, dan saling menghidupakan antarnggota masyarakat adat dengan alamnya. Penegasan ini mencerminkan adanya upaya menjaga keserasian, keselarasan, keseimbangan, dan keharmonisan antara manusia, alam dan Tuhan.

Nenggo yang menceritakan nilai kerukunan dan nilai persaudaraan sama yaitu yang bersyair; "Neka bike ca lide, neka behas ca cewak". Pengertian ungkapan; merupakan ekspresi dari harapan kiranya hidup manusia dalam masyarakat tetap satu, utuh, kompak, dan rukun. Isi ungkapannya berisi harapan yang mengajarkan supaya manusia menjaga, memelihara, membina persatuan, keutuhan, kekompakkan, dan kerukunan dalam kehidupan bersama. Syair dari Nenggo ini terdapat tiga makna yang dapat digali; pertama, menampilkan gagasan persatuan yang berusaha menghindarkan manusia dari bahaya perpecahan. Kedua, menyadarkan manusia bahwa persatuan merupakan sesuatu yang diperjuangkan, harus dipelihara, dan dijaga. Tanpa persatuan dengan yang lain, manusia sulit bekerja sama sebagai saudara, membina hubungan yang baik, dan akrab dengan orang lain. Ketiga, jika persatuan dan kesatuan terjaga dan terpelihara, maka kekompakan dan ketentraman dapat menjadi nyata dalam kebersamaan lonto ca golo, $\mathrm{ka}$ 'eng ca beo (hidup dalam persekutuan persaudaraan komunal).

\section{KESIMPULAN}

Nyanyian tradisi Aku Retang Baoadalah sebuah nyanyian tradisi Manggarai yang memiliki banyak manfaat untuk kehidupan masyarakat Manggarai. Nyanyian ini ditampilkan merupakan media penyampaian nilai-nilai kehidupan yang wajib dipatuhi oleh seluruh masyarakat Manggarai. Melalui syair syair berupa go'et, menjadikan nyanyian ini lazim dibawakan oleh orang-orang yang minimal berpengetahuan khusus dan ahli dalam menggunakan go'et-go'et sebagai peribahasa khas Manggarai. Secara umum pelantun nyanyian ini adalah mereka yang memiliki talenta khusus hasil keturunan dari orang tua dan para leluhur. Pelaku nyanyian ini mengalunkan nyanyian secara spontanitas sesuai dengan tema acara yang digelarkan. Tujuan utamanya adalah dapat menyampaikan dan merefleksi etika yang menjadi nilai kehidupan budaya masyarakat.

Nilai-nilai etika yang terkandung dalam nyanyian tradisi nenggo meliputi; 1)nilai kesenangan. Pada tingkat nilai terendah ini meliputi kesenangan pada penari caci atau pelaku nenggo (sebelum, ketika pertunjukan berlangsung, dan sesudah pertunjukan), kesenangan pada penonton (kesenangan dengan konsep dan manajemen pertunjukan tari caci, kesenangan dengan penari caci/ pelaku nenggo (melalui gerak, kostum, syair nenggo), dankesenangan dengan musik iringan pertunjukan tari caci; 2) Nilai vitalitas atau kehidupan yang mengandung hubungan dengan sesama dalam keluarga (ase ka' e), kebersamaan dalam kampung (lonto golo, ka'eng beo), relasi dengan orang lain (cama tau, ata bana), relasi dengan penguasa (ata tu'a laing); 3) Nilai spiritual, terdapat tiga pokok seperti nilai estetis, nilai benar dan salah, nilai dari pengetahuan murni demi diri sendiri; 4) Nilai Kesucian berkaitan dengan kepercayaan orang Manggarai diantaranya kepercayaan akan roh alam dan roh leluhur (ritus teing hang/takung dan ritus toto urat), kepercayaan akan adanya roh halus, benda dan ucapan magis, serta Mori kerang (Tuhan Pencipta).

\section{DAFTAR PUSTAKA}

Deki Kanisius.2011. Tradisi Lisan Orang Manggarai. Jakarta: Parrhesia Institute Jakarta. 
Hadarics, M., \& Kende, A. (2018). Moral foundations of positive and negative intergroup behavior: Moral exclusion fills the gap. International Journal of Intercultural Relations, 64, 67-76.

M. Adi Rahman. 2010. Mengenal Seni Musik Tradisional. Bandung : PT. Wacana Gelora Cipta.

Magid, R. W., \& Schulz, L. E. (2017). Moral alchemy: How love changes norms. cognition, 167, 135-150.

Muldma, M., \& Kiilu, K. (2012). Teacher's View on the Development of Values in Music Education in Estonia. ProcediaSocial and Behavioral Sciences, 45, 342350.

Nggoro Adi. 2016. Budaya Manggarai Selayang Pandang. Ende: Nusa Indah

Sutiyono, S. 2011. Tradisi Masyarakat sebagai Kekuatan Sinkretisme di Trucuk, Klaten. Jurnal Penelitian Humaniora, 16(1), 4559.
Sutiyono, S. 2017. Community identity politic of Brijo Lor society, Klaten in Ki Ageng Glego myth through Reog performance. Harmonia: Journal of Arts Research and Education, 17(2), 144-152.

Railton, P. (2017). Moral Learning: Conceptual foundations and normative relevance. Cognition, 167, 172-190.

Rachman, A. (2013). Bentuk dan Analisis Musik Keroncong Tanah Airku Karya Kelly Puspito. Harmonia: Journal Of Arts Research And Education, 13(1).

Rachman, A., \& Lestari, W. (2012). Bentuk Aransemen Musik Keroncong asli Karya Kelly Puspito dan Relevansinya Bagi Remaja Dalam Mengembangkan Musik Keroncong Asli. Catharsis, 1(2).

Widyaningrum, A. (2014). Orientasi Grup Vokal Awan Voice Pada Ideologi Pasar Musik Indonesia. Catharsis, 3(2). 